\title{
Pemphigoid and pemphigus antigens in cultured epidermal cells
}

\author{
LUIS A.DIAZ AND CYNTHIA L.MARCELO \\ Department of Dermatology, Immunodermatology Unit, University of Michigan Medical School, \\ Ann Arbor, Michigan 48rog, U.S.A.
}

Accepted for publication I November 1977

\section{SUMMARY}

Fractions of IgG from sera of patients with pemphigoid and pemphigus added to monolayer cultures of mouse epidermal cells resulted in a sparse distribution of cells. Direct immunofluorescence studies of these monolayers revealed epidermal cell surface antigens reacting with pemphigoid and pemphigus antibodies. We suggest that these antibodies may bind to epidermal cell surface antigenic molecules which are important in maintaining epidermal cell adhesion in culture.

Pemphigoid and pemphigus are diseases in which epidermal cell adhesion is abnormal (cell-to-cell in pemphigus and cell-to-basement membrane in pemphigoid). This defective adhesion process is associated with an auto-immune antigen/antibody reaction occurring on surfaces of epidermal cells, i.e. basal cells in pemphigoid, differentiating keratinocytes in pemphigus. We are studying the in vitro effects of pemphigoid, pemphigus and normal IgG fractions on mouse epidermal cells grown in culture to determine whether the epidermal cell adhesion defect and the autoimmune reaction are pathogenetically related. The present investigation was undertaken, first to determine the presence of pemphigus and pemphigoid antigens on mouse epidermal cells grown in culture, and second to detect changes in monolayer morphology that may occur as a result of the antigen/antibody reaction.

\section{MATERIALS AND METHODS}

Primary epidermal cell culture. Primary cultures of neonatal mouse epidermal cells (BALB/c) were prepared as described by Marcelo et al. (1977). Briefly, neonatal mouse epidermis was separated from the dermis by incubation in $0.25 \%$ trypsin (Difco, I:250, Detroit, Michigan) for $60 \mathrm{~min}$ at $37^{\circ} \mathrm{C}$. Gentle shaking of the isolated epidermis yielded a keratinocyte suspension that was further purified from dermis and fibroblasts by discontinuous Ficoll gradient centrifugation. The keratino-

Reprint requests to Dr L.A.Diaz.

Abbreviations: M-I99, medium 199; FCS, fetal calf serum; IF, immunofluorescence; CF-II, Cohn fraction II; PBS, phosphate buffered saline. 
cytes were washed with medium $199(\mathrm{M}-\mathrm{r} 99)+\mathrm{r} 3 \%$ fetal calf serum $(\mathrm{FCS})+50 \mathrm{IU} / \mathrm{ml}$ of penicillin and $50 \mathrm{mcg} / \mathrm{ml}$ of streptomycin (Flow Labs, Rockville, Maryland) and counted. $1 \cdot 8 \times 10^{6}$ trypan blue excluding cells were inoculated into Costar plastic Leighton tubes containing a non-fluorescent plastic coverslip and M-199+FCS to give a final volume of $2 \mathrm{ml}$. The tubes were gassed with a $5 \% \mathrm{CO}_{2}$ in air mixture and incubated at $32-33^{\circ} \mathrm{C}$. Nutrients were added to the cultures every other day.

Immunofluorescent $(I F)$ techniques. Indirect and direct IF staining was performed by previously established methods (Beutner, Chorlzelski \& Jordon, 1970). Cryostat cut sections of neonatal or adult mouse tongue were used as substrates for indirect IF studies. Treated and control epidermal monolayers were also used for direct IF. Fluorescein-conjugated goat anti-human IgG serum (Molar F/P ratio $2 \cdot 7$, Meloy Laboratories, Springfield, Va.) was employed in both procedures. Blocking experiments were performed by pre-incubating the epidermal monolayers with unlabelled goat antihuman IgG serum (Hyland Div., Travenol Labs., Costa Mesa, Ca.) and then performing the direct IF procedure.

Sera. Pemphigus vulgaris and bullous pemphigoid sera were heat inactivated and then absorbed with human erythrocytes $\left(\mathrm{A}, \mathrm{B}, \mathrm{O}, \mathrm{LeA}^{+}, \mathrm{LeB}^{+}\right)$. The $\mathrm{IgG}$ fraction of each serum was purified by ammonium sulphate precipitation and DEAE-cellulose chromatography (Fahey \& Terry, 1973). The purified IgG fractions were adjusted to a known protein concentration and the indirect IF titre determined (pemphigus IgG, $19 \cdot 3 \mathrm{mg} / \mathrm{ml}$, IF titre $\mathrm{I}: 320$; pemphigoid IgG, $7.69 \mathrm{mg} / \mathrm{ml}$, IF titre $1: 160$ ).

Experimental design. Four triplicate sets of cultures in Leighton tubes were prepared. Human IgG fractions were diluted in culture medium (M-199+13\% FCS) and added to the tubes at day o (time of inoculation) and at each subsequent medium change. The tubes were coded as follows: (I) 300 $\mu \mathrm{g} / \mathrm{ml}$ of human IgG (CF-II, Sigma, St. Louis, Mo.); (2) $400 \mu \mathrm{g} / \mathrm{ml}$ of pemphigoid IgG; (3) $500 \mu \mathrm{g} / \mathrm{ml}$ of pemphigus IgG; and (4) no additives. Each group was studied on days $0,2,4$ and 7 . The coverslips coated with cultured epidermal cells were cut in half; one half was used as a substrate for direct IF examination and the other was fixed with acetic acid/ethanol and stained with haematoxylin/eosin for studies of monolayer morphology.

\section{RESULTS}

Tissue substrate. Purified pemphigus and pemphigoid IgG reacted with mouse tongue epithelia producing the typical staining patterns described in other mammalian tissues (Beutner, Chorlzelski \& Jordon, 1970).

Epidermal cell suspension. On day o, the suspension of epidermal cells displayed some variation in the degree of binding with pemphigus and pemphigoid antibodies. Some cells showed the staining patterns previously described by others (Brigden \& Amos, 1975). However, in other batches of cells, these staining features were absent or difficult to differentiate from those produced by normal human IgG (CF-II).

Epidermal monolayer morphology. The normal growth and differentiation of neonatal mouse epidermal cells grown in culture have been described in detail by Marcelo et al. (1977), employing light microscopy, scanning and transmission electron microscopy as well as histochemical techniques. Briefly, under ideal conditions, the epidermal cells will cover about $80 \%$ of the surface substrate by day 2. Individual cells are hexagonal with a large nucleus and a rough cell surface. By day 3 or 4 a complete monolayer is formed as seen in Fig. ra. Culture stratification is seen by day 5 or 6 , and by day I2-I4 there is a massive 'pile up' of 'rounded bodies' which are degenerating specialized cells.

Control monolayers. Epidermal cells grown in medium containing human IgG (CF-II) or in IgGfree medium showed normal monolayer morphology throughout the study (Figs Ia, Ib, 2a, 2b). 

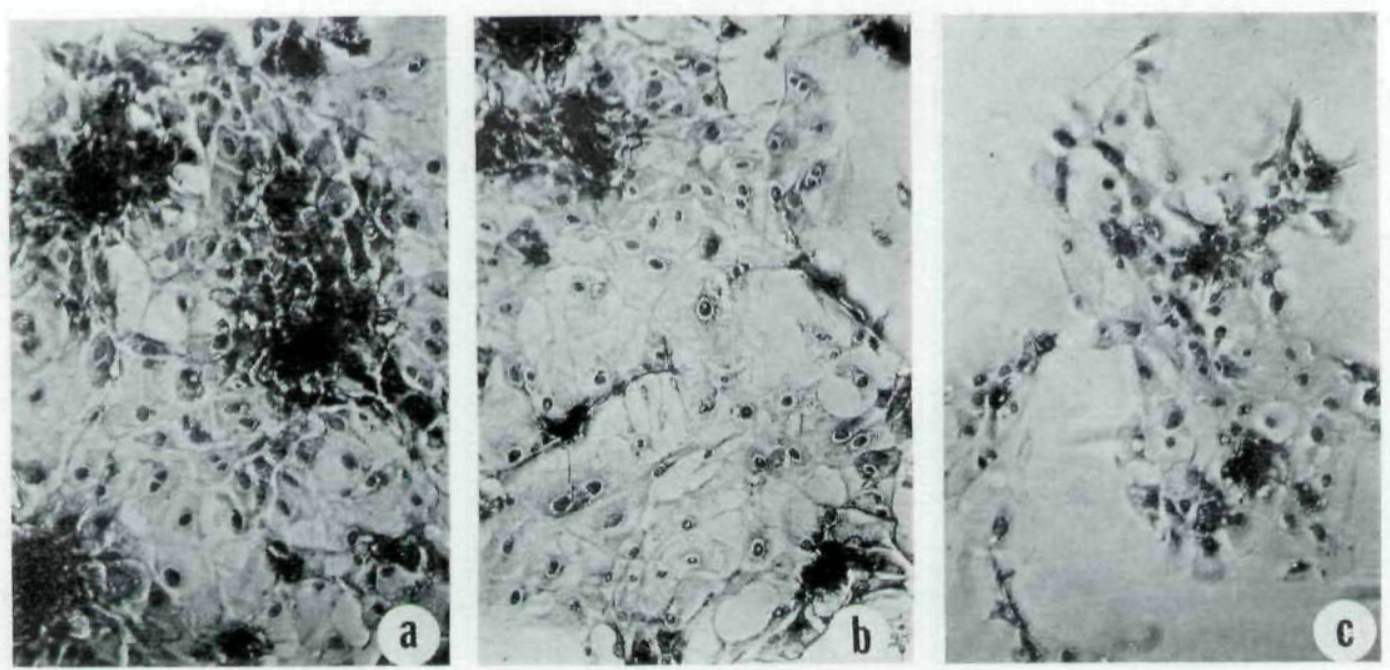

FIGURE I. Epidermal monolayers (4 days after inoculation); (a) grown in human IgG-free media, (b) grown in human IgG (CF-II), and (c) grown in pemphigoid IgG ( $\times$ I15).
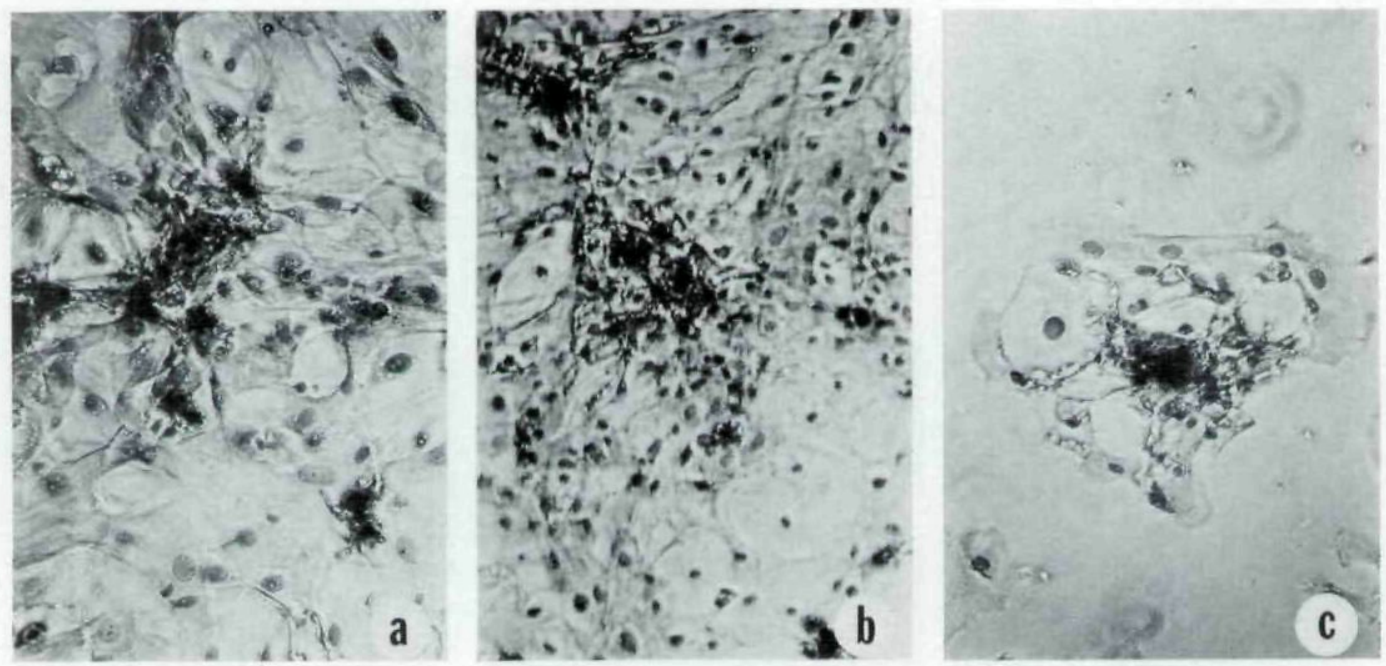

FIGURE 2. Epidermal monolayers ( 7 days after inoculation); (a) grown in human IgG-free media $(\times 230),(b)$ grown in human IgG (CF-II) ( $\times$ II5), and (c) grown in pemphigus $\operatorname{IgG}(\times 230)$.

Direct IF studies of these monolayers revealed a yellowish-brown staining of the cells on days 2, 4, and 7 that was interpreted as a negative result (Fig. 3a). Some degenerated epidermal cells attached to the surface of the monolayer stained diffusely.

Pemphigoid-treated monolayers. Most monolayers treated with pemphigoid IgG showed a marked sparseness on days 2 and 4 . Less than $60 \%$ of the substrate surface was covered by cells (Fig. IC). These cells were seen in colonies or as single elements. However, several pemphigoid IgG-treated cultures, after this initial change, resembled the cellular density of control cultures by day 7 . Through- 

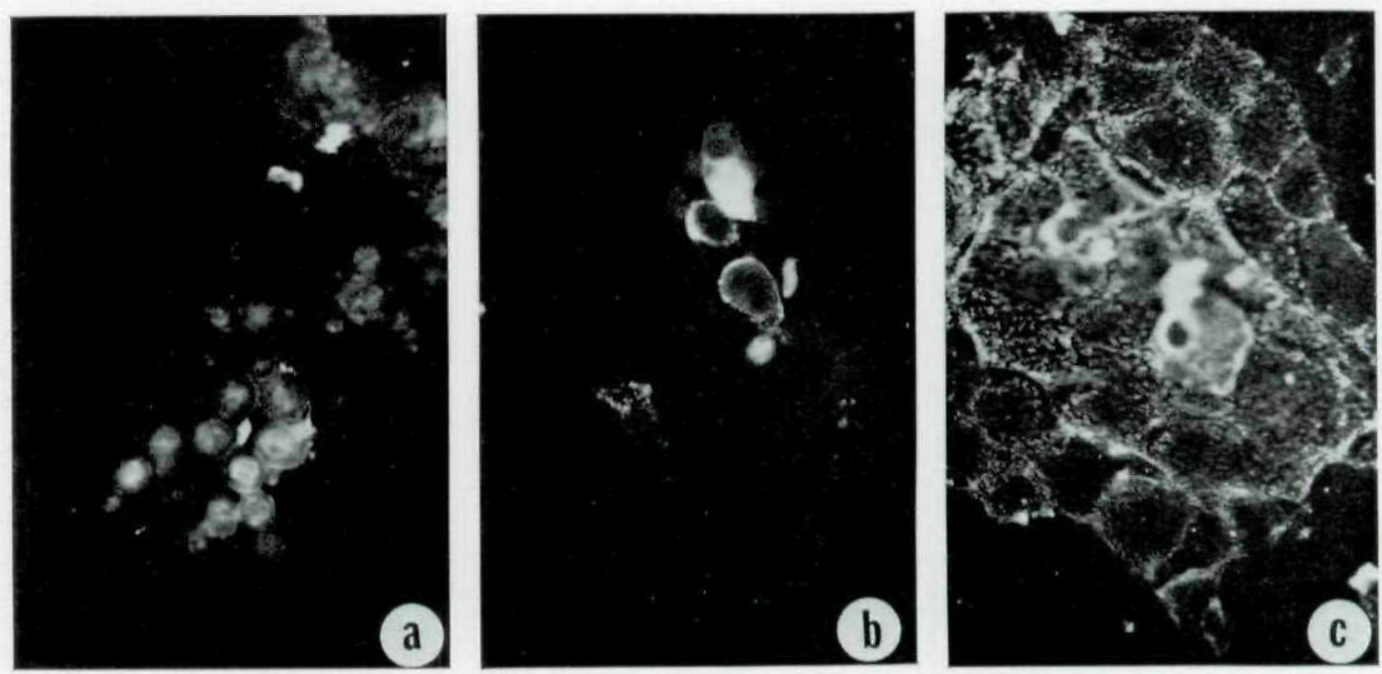

FIGURE 3. Direct IF studies of epidermal monolayers grown in human IgG fractions (2 days after inoculation); (a) IgG (CF-II), (b) pemphigoid IgG, and (c) pemphigus IgG ( $\times 3$ Io).

out the experiment, the cells which did attach to the coverslip showed normal morphology. By direct IF examination only a small number of the epidermal cells comprising the monolayers fixed pemphigoid IgG. These single cells were usually found in the space separating colonies of epidermal cells. The reacting cells were oval or elongated showing a granular staining of the cell surface. Occasionally these cells showed a polar rim of fluorescence (Figs 3 b \& 4 a). Few cells bound pemphigoid antibodies, approximately 3 per field $(\times 310)$ on day 2 . Such cells were scarce on day 4 and only
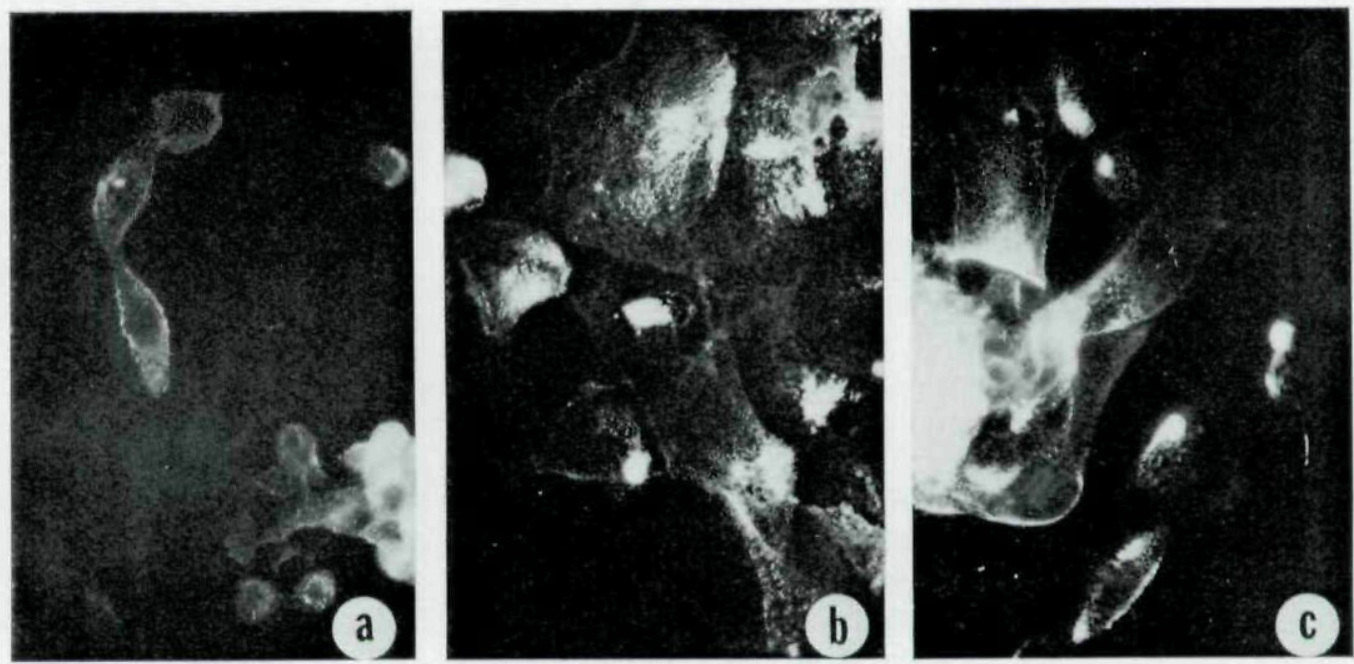

FIGURE 4. Direct IF studies of epidermal monolayers grown in human IgG fractions (4 days after inoculation); (a) pemphigoid IgG, (b and c) pemphigus IgG ( $\times 3 \mathrm{IO})$. 
occasionally found on day 7 . The staining of the epidermal cells was specifically abolished by pretreatment of the monolayer with unlabelled goat antihuman IgG. Colonies of epidermal cells scattered on the slide showed no fluorescence.

Pemphigus-treated monolayers. Monolayers treated with pemphigus antibodies showed normal development until day 4 , when some of the cultures became sparse. By day 7 , most cultures showed altered morphology and were sparse (Fig. 2c). The attached epidermal cells in these sparse monolayers were flat and scattered on the coverslip surface. No evidence of stratification was observed. The surface of plated epidermal cells reacted by direct IF with pemphigus antibodies producing staining patterns that changed as the culture grew older. On day 2 , keratinocytes grouped in colonies reacted with pemphigus antibodies giving a honeycomb appearance to the cell colony (Fig. $3 \mathrm{c}$ ). The surface staining of the individual cells was granular and irregular (Fig. 3c). On days 4 and 7 , the surface of the cells which remained attached to the substrate appeared granular and clumpy. The reacting antigens in these cells coalesced into an amorphous mass as seen in Figs $4 \mathrm{~b}$ and $4 \mathrm{c}$. The staining of the cell surface produced by pemphigus antibodies was prevented by pre-incubation of the monolayers with unlabelled goat antihuman IgG sera.

\section{DISCUSSION}

This study has shown, firstly, that the addition of pemphigoid and pemphigus IgG fractions alter the monolayer morphology of neonatal mouse epidermal cells grown in culture. Untreated control cultures or cultures treated with normal human IgG (CF-II) did not show these changes. The addition of pemphigoid and pemphigus IgG fractions caused the monolayers to become sparse. The changes produced by the pemphigoid IgG fraction were detected mainly on days 2 and 4 , whereas pemphigus IgG treated cultures showed alterations in morphology beginning on day 4. A direct complementdependent cytotoxic effect of these autoantibodies on epidermal cells may account for the low density of cells coating the coverslip substrate. However, another attractive explanation for this phenomenon is that pemphigoid and pemphigus antibodies bind cell surface molecules which are important in maintaining epidermal cell adhesion in culture. Both possibilities are being investigated. Pemphigus antibodies have been found to be noncytotoxic to guinea-pig epidermal cells (Takigawa \& Imamura, 1977). However, pemphigus IgG fractions are known to induce acantholysis in epidermis grown in the organ culture system (Schlitz \& Michel, 1976).

The second finding reported in this paper is the detection by direct IF of antigens reacting with pemphigoid and pemphigus antibodies on the surface of epidermal cells grown in culture. The specificity of this reaction was verified by blocking experiments with unlabelled goat antihuman IgG. Neither untreated epidermal cells nor cells treated with normal human IgG (CF-II) showed surface fluorescence. Pemphigus and pemphigoid antigens detected on epidermal cells in suspension (day o) showed IF patterns previously reported (Brigden \& Amos, 1975). However, we found that these features on occasion were absent or difficult to differentiate from those produced by normal human (CF-II). These variable results may depend on the amount of antigen available on the epidermal cell surface on day 0 . Trypsinization and repeated washing during experimental procedures may remove these antigens which are known to be PBS-soluble (Shu \& Beutner, 1973; Diaz et al., 1977). Several presently unknown factors may account for the detection of a small and decreasing number of epidermal cells bearing pemphigoid antigen, such as the limits of sensitivity of IF techniques, the decreasing number of cells producing this antigen as a culture grows older, and that most cells after binding pemphigoid antibodies are unable to plate normally for the reasons previously mentioned and therefore slough off the substrate during culture and IF procedures.

Pemphigus antigen, however, was present on the surface of cells grouped in colonies, producing a 
honeycomb appearance. Starting at day 4 , the granular pemphigus antigen agglutinated on the cell surface producing an amorphous mass. This phenomenon probably represents a capping-like effect described in other cell surface antigen/antibody systems (Carey, Kuhn \& Hardford, 1965; Yefenoy \& Klein, 1974; Schreiner \& Unanue, 1976). It is unclear if this phenomenon is related to the onset of cellular detachment observed in pemphigus treated monolayers.

Several investigations confirm the importance of certain cell surface antigens in the adhesion or aggregation phenomenon of cells (Moscona, 1974; Pearlstein, 1976; Rutishauser et al., 1976; Yamada, Yamada \& Pastan, 1976; Klebe et al., 1977; Poussegur, Willingham \& Pastan, 1977; Öbrink, Kuhlenschmidt \& Roseman, 1977; Ali et al., 1977). Furthermore, antibodies against these cell surface antigens when added to cells bearing such antigens are known to impair the cell adhesion or aggregation of these cells (Ali et al., 1977; O’Neill \& Follett, 1970; Beug, Katz \& Gerisch, 1973; Rosen, Haywood \& Barondes, I976), to alter phagocytosis (Carey \& Pettengill, 1967) and to induce morphological changes in these cells causing them to become rounded (Yamada et al., I976; Ali et al., 1977; O'Neill \& Follett, 1970). It is important to note that acantholytic cells found in pemphigus lesions are rounded and demonstrate surface bound antibodies (Wolff \& Schreiner, 197I). A hypothesis being explored experimentally in our laboratory is that pemphigoid and pemphigus antigens are important in maintaining epidermal cell-to-cell (pemphigus) and cell-to-basement membrane (pemphigoid) adhesion. The antibodies produced by afflicted patients would interfere with epidermal cell adhesion in vivo.

\section{ACKNOWLEDGMENT}

This investigation was supported by NIH Biomedical Research Support Grant no. RR-05383 and NIH Grant no. AM-I 5740.

\section{REFERENCES}

Ali, I.U., Mautner, V., LANZA, R. \& Hynes, R.O. (1977) Restoration of normal morphology, adhesion and cytoskeleton in transformed cells by addition of a transformation-sensitive surface protein. Cell, II, II5.

Beutner, E.R., Chorzekski, T.P. \& Jordon, R.E. (1970) Autosensitization in Pemphigus and Bullous Pemphigoid. Charles C. Thomas, Springfield, IIl.

BeUG, H., KATZ, F.E. \& GeRISCH, G. (r973) Dynamics of antigenic membrane sites relating to cell aggregation in Dictyostelium discoideum. Fournal of Cell Biology, 56, 647 .

BRIGDEN, W.D. \& AMOS, H.E. (1975) The differential binding of antibody from the sera of patients with pemphigus and pemphigoid to isolated guinea-pig epidermal cells. British fournal of Dermatology, 93, 425.

CAREY, F.J., KuHN, N.O. \& HARFORD, C.G. (1965) Effects of anticellular serum on phagocytosis and the uptake of tritiated thymidine and uridine by HeLa cells. Fournal of Experimental Medicine, 121, 991.

Carey, F.J. \& Pettengill, O.S. (I967) Time-lapse study of effects of antibody in membrane mobility and phagocytic activity of HeLa cells. Fournal of Cell Biology, 33, 709.

Diaz, L.A., Calvanico, N.J., Tomasi, T.B., Jr \& Jordon, R.E. (r977) Bullous pemphigoid antigen: isolation from normal human skin. Fournal of Immunology, $\mathbf{x} \mathbf{8} 8,455$.

FAHEY, J.L. \& TERRY, E.W. (I973) Ion exchange chromatography and gel filtration. In: Handbook of Experimental Immunology, Immunochemistry (Ed. by D.M. Weir), Vol. I, p. 7· I Blackwell Scientific Publications, Oxford.

Klebe, R.J., Rosenberger, P.G., Naylor, S.L., Burns, R.L., NovaK, R. \& Kleinman, H. (r977) Cell attachment to collagen. Isolation of a cell attachment mutant. Experimental Cell Research, ro4, Ir9.

Marcelo, C.L., Kim, Y.G., KaINe, J. \& Voorhees, J.J. (r977) Stratification and specialization of primary keratinocyte culture: Evidence of a functioning in vitro epidermal cell system. Submitted for publication.

Moscona, A.A. (1974) Surface specification of embryonic cells: lectin receptors cell recognition and specific cell ligands. In: The Cell Surface Development (Ed. by A.A. Moscona), p. 67. John Wiley and Sons, New York.

O'NeILL, C.H. \& Follett, E.A.C. (I970) An inverse relation between cell density and the number of microvilli in cultures of BHL 2 I hamster fibroblasts. Fournal of Cell Science, 7, 685. 
ÖBrink, B., KuHLensChmidt, M.S. \& Roseman, S. (1977) Adhesive specificity of juvenile rat and chicken liver cells and membranes. Proceedings of the National Academy of Sciences, U.S.A., 74, 1077.

Pearlstein, E. (1976) Plasma membrane glycoprotein which mediates adhesion of fibroblasts to collagen. Nature, 262, 497.

Pouyssegur, J., Willingham, M. \& Pastan, I. (1977) Role of cell surface carbohydrates and proteins in cell behavior: Studies on the biochemical reversion of an $\mathrm{N}$-acetylglucosamine-deficient fibroblast mutant. Proceedings of the National Academy of Sciences, U.S.A., 74, 243.

Rutishauser, U., Thiery, J.P., Brackenbury, R., Sel., B.A. \& Edelman, G.D. (1976) Mechanisms of adhesion among cells from neural tissues of chick embryo. Proceedings of the National Academy of Sciences, U.S.A., 73,577 .

Rosen, S.D., Haywood, P.L. \& BARONDES, S.H. (1976) Inhibition on intercellular adhesion in a cellular slime mold by univalent antibody against a cell-surface lectin. Nature, 263, 425 .

SHU, S. \& BeUTNER, E.H. (1973) Isolation and characterization of antigens reactive with pemphigus antibodies. Fournal of Investigative Dermatology, 6r, 270.

Schlitz, J.R. \& Michel, B. (1976) Production of epidermal acantholysis in normal human skin in vitro by the IgG fraction from pemphigus serum. Fournal of Investigative Dermatology, 67, 254.

SCHREINER, G.F. \& UNANUE, E.R. (I976) Membrane and cytoplasmic changes in B lymphocytes induced by ligand-surface immunoglobulin interaction. Advances in Immunology, 24, 38.

TAKigaWA, M. \& IMAMURA, S. (I977) Experimental production of rabbit anti-guinea-pig epidermal cell sera. Comparison to pemphigus antibodies. Fournal of Investigative Dermatology, 68, 254.

WOLFF, K. \& SCHREINER, E. (I97I) Ultrastructural localization of pemphigus auto-antibodies within the epidermis. Nature, 229, 59 .

YEFENOF, E. \& KLEIN, G. (1974) Antibody induced redistribution of normal and tumor associated surface antigens. Experimental Cell Research, 88, 217.

YAMADA, K.M., YAMADA, S.S. \& PASTAN, I. (1976) Cell surface protein partially restores morphology, adhesiveness, and contact inhibition of movement to transformed fibroblasts. Proceedings of the National Academy of Sciences, U.S.A., 74, 1077. 
This document is a scanned copy of a printed document. No warranty is given about the accuracy of the copy. Users should refer to the original published version of the material. 